\title{
Improving Outcomes of Neuroprotection by Minocycline
}

\section{Guides from Cell Culture and Intracerebral Hemorrhage in Mice}

\author{
Mengzhou Xue, ${ }^{\star \dagger}$ Elena I. Mikliaeva, ${ }^{\ddagger}$ \\ Steve Casha, ${ }^{* \dagger}$ David Zygun, ${ }^{* \dagger}$ \\ Andrew Demchuk, ${ }^{* \dagger}$ and V. Wee Yong ${ }^{* \dagger}$ \\ From the Hotchkiss Brain Institute," Clara Christie Centre for \\ Mouse Genomics and Modelling of Human Disease, ${ }^{\ddagger}$ and \\ Departments of Clinical Neurosciences, ${ }^{\dagger}$ and Medicine, ${ }^{\$}$ \\ University of Calgary, Calgary, Alberta, Canada
}

Minocycline ameliorates deficits in models of acute and chronic neurological diseases, but many publications do not replicate these results. We tested the hypothesis that a key factor in achieving neurological benefits is the exposure of neural cells to local high concentrations of minocycline. This hypothesis was evaluated by using human neurons in culture and in a mouse model of intracerebral hemorrhage (ICH). In culture, neurons were very vulnerable to blood-induced toxicity, with $60 \%$ lost within 24 hours in an environment of $5 \%$ blood in culture medium. Minocycline reduced blood-induced neurotoxicity in a concentration-dependent manner. In vivo, the introduction of blood into the striatum of mice to simulate ICH resulted in a massive lesion by 24 hours. When minocycline was mixed with the blood used to inflict ICH, the resulting extent of neuropathology was significantly less than that achieved with intraperitoneal administration of medication. The combination of intracerebral and intraperitoneal minocycline improved neuroprotection compared with either alone. We then delayed minocycline treatment and injected it into the hematoma 1 hour after ICH. We found greater alleviation of brain damage and neuronal death with increasing concentrations of minocycline injected locally, which was reflected in limited behavioral and histological recovery. We conclude that the prospect of neuroprotection with minocycline is improved by high concentrations of minocycline delivered locally into the central nervous system with supplementation from sys- temic administration. (Am J Pathol 2010, 176:1193-1202; DOI: 10.2353/ajpath.2010.090361)

Minocycline is a semisynthetic tetracycline that alleviates the degree of neuropathology in animal models of several neurological disorders, including stroke, ${ }^{1,2}$ spinal cord injury, ${ }^{3,4}$ multiple sclerosis, ${ }^{5,6}$ and Parkinson's disease. ${ }^{7,8}$ Minocycline has multiple effects that may account for alleviation of tissue injury, such as matrix metalloproteinase (MMP) inhibition, anti-inflammatory, antioxidant, and antiapoptotic properties. ${ }^{9-12}$ These studies have led to clinical trials of minocycline in multiple sclerosis, ${ }^{13-15}$ amyotrophic lateral sclerosis (ALS), ${ }^{16}$ stroke, ${ }^{17}$ and spinal cord injury (clinicaltrials.gov, identifier NCT00559494). The available clinical results have been mixed; minocycline was reported to worsen ALS in a Phase III study, ${ }^{16}$ but it provided benefits in small trials in stroke ${ }^{17}$ and multiple sclerosis. ${ }^{13-15}$

While the varied outcomes of minocycline in ALS, multiple sclerosis, and stroke may reflect the different pathophysiology of these disorders with particular sensitivity to the medication, it is noteworthy that conflicting data for minocycline have also emerged from preclinical studies of specific disorders. Using intracerebral hemorrhage

Supported by an operating grant from the Canadian Institutes of Health Research.

M.X. was supported by fellowships from the Canadian Institutes of Health Research and Alberta Heritage Foundation for Medical Research and is currently a holder of a fellowship from Focus on Stroke Canadian Institutes of Health Research /Rx and D Collaborative Research Program. V.W.Y. is an Alberta Heritage Foundation for Medical Research Scientist and a Canada Research Chair (Tier 1) holder.

Accepted for publication November 17, 2009.

Supplemental material for this article can be found on http://ajp. amjpathol.org

Address reprint requests to V. Wee Yong, Ph.D., University of Calgary, 3330 Hospital Drive, Calgary, Alberta T2N 4N1, Canada. E-mail: vyong@ ucalgary.ca. 
$(\mathrm{ICH})$ and ischemia in rodents as an example (Supplemental Table 1, see http://ajp.amjpathol.org), ${ }^{1,2,18-27} \mathrm{mi}$ nocycline administrated through the i.p. route at 45 $\mathrm{mg} / \mathrm{kg} 1$ hour after $\mathrm{ICH}$ reduced neural cell death and improved behavioral recovery. ${ }^{28}$ Other authors, however, described that the administration of $45 \mathrm{mg} / \mathrm{kg}$ minocycline by intravenous route from 6 hours after $\mathrm{ICH}$, followed by i.p. injections at 24, 48, and 72 hours, failed to reduce neuronal loss adjacent to the hematoma at 7 days, despite decreasing the number of neutrophils and activated microglia/macrophages. ${ }^{19}$ Another study showed that when $45 \mathrm{mg} / \mathrm{kg}$ of minocycline was applied 3 and 12 hours after ICH by i.p. injections, followed by $22.5 \mathrm{mg} / \mathrm{kg}$ twice daily i.p. for another 4 days, it provided neither protection of neuronal loss nor behavioral benefits at 5 or 8 days, even though the activation of microglial/ macrophage was significantly reduced in the perihematoma region. ${ }^{18}$ In contrast, Wu et al ${ }^{20}$ reported that i.p. minocycline, initiated at $45 \mathrm{mg} / \mathrm{kg}$ immediately and 12 hours after $\mathrm{ICH}$ followed by $22.5 \mathrm{mg} / \mathrm{kg}$ twice a day for 2 days, reduced perihematomal brain edema in rats at day 3 and attenuated neurological deficits and brain atrophy at day 28 .

The discrepancies noted for neuroprotection by minocycline remain unclear, but confounding factors include the dose, its route of administration, and the timing of when minocycline treatment is initiated; the $\mathrm{ICH}$ studies mentioned above tended to have improved outcomes when minocycline was initiated early. These factors influence the desired concentration of minocycline that can be achieved locally and quickly at sites of action. In this study, we have tested the hypothesis that a key factor to achieving successful outcome with minocycline is the local exposure of neural cells to high concentrations of this medication. We have used human neurons in culture and a mouse model of $\mathrm{ICH}$ in our studies. The results could provide guides on how to improve the potential of neuroprotection by minocycline in acute neurological insults.

\section{Materials and Methods}

\section{Evaluation of Neuronal Survival in Culture Treated with Blood and Minocycline}

Human neurons were isolated from the brain of fetuses of 15 to 22 weeks gestation that were obtained through legal and therapeutic abortions. The use of these specimens was approved by local institutional human ethics committee. The detailed techniques and methods for preparing the human neurons have been described previously ${ }^{29,30}$; the purity of neurons is in excess of $80 \%$ with the remaining cells being predominantly astrocytes. The neuron-enriched cells originally seeded into flasks were retrypsinized and plated at 100,000 cells/well in 16-well Lab-tek slides (Nunc, Naperville, IL) for experiments. The neurons were 2 weeks in culture when they were used for experiments.

Thirty minutes before an experiment was initiated, the serum-containing ( $10 \%$ fetal bovine serum) medium was switched to a serum-free AIM-V medium (Invitrogen, Bur- lington, ON), so that factors in serum would not confound the experimental results. One, 2.5 , or $5 \mu$ l of fresh human blood collected from a pin-prick of the finger of volunteers were added to the 100- $\mu$ l medium that nourished the neurons within each well of the 16-well slides. In the experiments involving minocycline, the medication was added to wells 10 minutes before blood. It is important to note that the minocycline solution was prepared fresh in PBS before its use on a given day.

We used concentrations of minocycline at 10,20, and 40 $\mu \mathrm{g} / \mathrm{ml}$ because levels of $10 \mu \mathrm{g} / \mathrm{ml}$ of minocycline are achieved in the serum of mice treated with minocycline that alleviates symptoms of experimental autoimmune encephalomyelitis. ${ }^{31}$ Moreover, in the recently completed clinical trial of minocycline in spinal cord injury at the University of Calgary (clinicaltrials.gov, identifier NCT00559494), levels of 10 to $30 \mu \mathrm{g} / \mathrm{ml}$ minocycline have been found in the serum of patients after they received an intravenous high-dose delivery (unpublished results).

Forty-eight hours after treatment with blood, neurons were fixed with $4 \%$ paraformadehyde and incubated with mouse anti-human microtubule-associated protein-2 antibody (Sigma, St. Louis, MO; 1:2000) for 1 hour. A goat anti-mouse Ig conjugated to Cy3 (Caltag Laboratories, Burlingame, CA; 1:300) was used for another hour. Hoechst dye (Sigma; nuclear yellow, 1:100) was applied to label all nuclei, ${ }^{29}$ and the Lab-tek slides were coverglassed for immunofluorescence microscopy. The designated four fields of each well using $40 \times$ objective lens were enumerated for the number of neurons present. The number of neurons per well was summed from the fields counted and expressed as a percent of that present in control wells not exposed to blood or minocycline. These results are presented in Figure 1, A and B.

\section{$\mathrm{ICH}$ in Mice}

All experimental procedures were done in accordance with the Canadian Council on Animal Care. Protocols were approved by the University of Calgary local experimental ethics committee. Adult (8 to 10 weeks old) CD-1 male mice were used and were purchased from Charles River Laboratories Canada (St. Constant, Quebec).

To mimic the sudden collection of blood in the brain in $\mathrm{ICH}$, the model induced by autologous blood was used as previously described. ${ }^{30,32}$ In brief, ketamine/xylazine (85 mg/kg and $15 \mathrm{mg} / \mathrm{kg}$, respectively) anesthetized mice were immobilized in a stereotactic apparatus (KOPF). A midline scalp incision was made, and a hole was drilled in the right skull $(2.5 \mathrm{~mm}$ lateral to midline, $0.02 \mathrm{~mm}$ anterior to coronal suture). Autologous blood (10 $\mu$ l) was collected into a sterile insulin syringe without any anticoagulant by cutting the tip of the tail. The end of the needle of the blood-filled syringe was stereotaxically lowered 4.5 $\mathrm{mm}$ below the surface of the brain through the drilled hole in the skull. Injection of $10 \mu \mathrm{l}$ of blood was performed over 3 minutes, and the needle was then left in place for another 3 minutes to minimize backflow. After withdrawal of the needle, the scalp was sutured, and animals were heated by using a temperature-controlled $\left(27^{\circ} \mathrm{C}\right)$ veteri- 

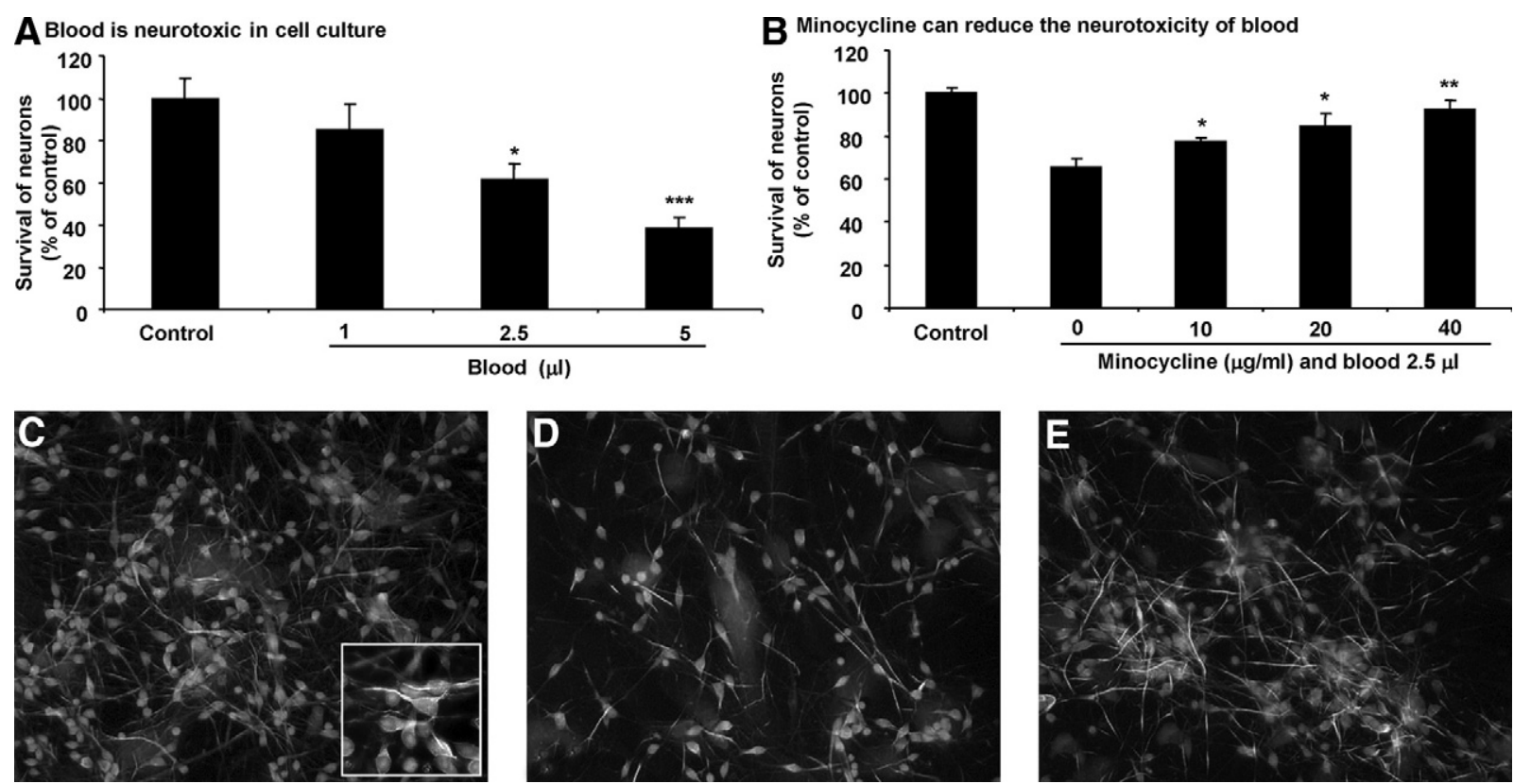

Figure 1. Minocycline reduces the neurotoxicity of blood in culture in a concentration-dependent manner. A: Blood added to culture medium kills neurons in a concentration-dependent manner. B: The toxicity of $2.5 \mu \mathrm{l}$ of blood added to $100-\mu \mathrm{l}$ culture medium is attenuated by minocycline; the highest concentration of $40 \mu \mathrm{g} / \mathrm{ml}$ minocycline afforded the best protection. Results are expressed as the percent of neurons remaining in culture compared with that in control cultures, where an average of 215 neurons were counted over four fields per well. Each bar is the mean \pm SD of quadriplicate wells. ${ }^{*} P<0.05$; ${ }^{* *} P<0.01 ;{ }^{* * *} P<0.001$ compared with controls. The results of $\mathbf{A}$ and $\mathbf{B}$ are reproduced in two other sets of cultures. Not displayed is that minocycline (10, 20 , and $40 \mu \mathrm{g} / \mathrm{ml}) \mathrm{by}$ itself did not result in loss of neurons. C-E (original magnification, $\times 200$ ) depict microtubule-associated protein-2 stained neurons with Hoechst dye labeling of nuclei, depicting control $(\mathbf{C})$, cultures treated with $2.5 \mu \mathrm{l}$ of blood $(\mathbf{D})$, or $2.5 \mu \mathrm{l}$ of blood plus $20 \mu \mathrm{g} / \mathrm{ml}$ minocycline. The inset in $\mathbf{C}$ shows neurons magnified.

nary recovery chamber (Harvard Apparatus, Quebec, Canada) until recovery from surgical anesthesia was complete. Animals were returned to their cages with free access to food and water. As a control for $\mathrm{ICH}$, an equivolume of $10 \mu \mathrm{l}$ of PBS was deposited into the striatum.

\section{Pharmacological Treatment of ICH Animals}

To attempt inhibition of the neurotoxicity of blood, mice were injected either intracerebrally or intraperitoneally (IP), or a combination of both routes, with minocycline or PBS (Figure 2, A-F). The first group of mice received the first treatment dose at the time of $\mathrm{ICH}$. Here, a subset was treated with $50 \mathrm{mg} / \mathrm{kg}$ minocycline or PBS IP, while another received $2 \mu$ l of PBS or minocycline added to the 10 $\mu \mathrm{l}$ of blood that was used to inflict $\mathrm{ICH}$ injury; this latter group is henceforth called "intracerebral" (IC). The concentration of minocycline in the $10 \mu \mathrm{l}$ of blood was 10 $\mu \mathrm{g} / \mathrm{ml}$. A third subset of mice received both treatment protocols $(I C+I P)$. Because the half-life of minocycline in rodents is of the order of 2 hours, ${ }^{33,34}$ all mice regardless of the nature of initial treatment received a second injection of minocycline $(50 \mathrm{mg} / \mathrm{kg}$ ) or PBS at 12 hours after $\mathrm{ICH}$, and these were administered only through the IP route. Mice were sacrificed at 24 hours after $\mathrm{ICH}$ for histological analyses. In previous studies, ${ }^{30,32}$ a significant area of brain damage was clearly measurable by 24 hours of $\mathrm{ICH}$. Moreover, our published ${ }^{28}$ and unpublished results have determined that minocycline does not alter the body temperature of rodents; this is important because hypothermia can be neuroprotective in certain context.
It should be noted that mice were given either minocycline or PBS at all indicated times, with no cross-over of treatment. The dose of $50 \mathrm{mg} / \mathrm{kg}$ minocycline IP mimicked that which we had previously administered to mice to improve their recovery from experimental autoimmune encephalomyelitis ${ }^{5}$ or spinal cord injury. ${ }^{3}$ Higher doses were not found to be compatible with the survival of rodents.

In another group to approximate the delayed treatment of patients, mice were first subjected to $\mathrm{ICH}$ as described above, and minocycline or PBS vehicle treatment was then initiated from 1 hour after injury (Figure 3, A-C). Medications were given both IC and IP (50 mg/kg minocycline or PBS), whereby $2 \mu$ l solution of minocycline or PBS was injected by using a Hamilton syringe into the parenchyma of the striatum where the hematoma is expected to be located. The final concentration of minocycline administered IC was calculated to be 10 to $40 \mu \mathrm{g} / \mathrm{ml}$ based on a hematoma volume (which we assumed to equate the volume of blood injected into the striatum) of $10 \mu \mathrm{l}$. All mice received additionally an IP injection of minocycline $(50 \mathrm{mg} / \mathrm{kg}$ ) or PBS 12 hours after $\mathrm{ICH}$ and were sacrificed at 24 hours after $\mathrm{ICH}$ for histological evaluations.

A last group of mice for long-term outcomes was maintained for 3 weeks after $\mathrm{ICH}$ for behavioral indices and histological scores. The mice were treated at 1 hour after $\mathrm{ICH}$ by using minocycline in both IC $(40 \mu \mathrm{g} / \mathrm{ml})$ and IP (50 $\mathrm{mg} / \mathrm{kg}$ ) routes as indicated above. Because this was a chronic experiment, we administered an additional 50 $\mathrm{mg} / \mathrm{kg}$ IP at 12 hours, then $50 \mathrm{mg} / \mathrm{kg}$ IP twice a day for the next 3 days, and which was then tapered to $50 \mathrm{mg} / \mathrm{kg}$ per 

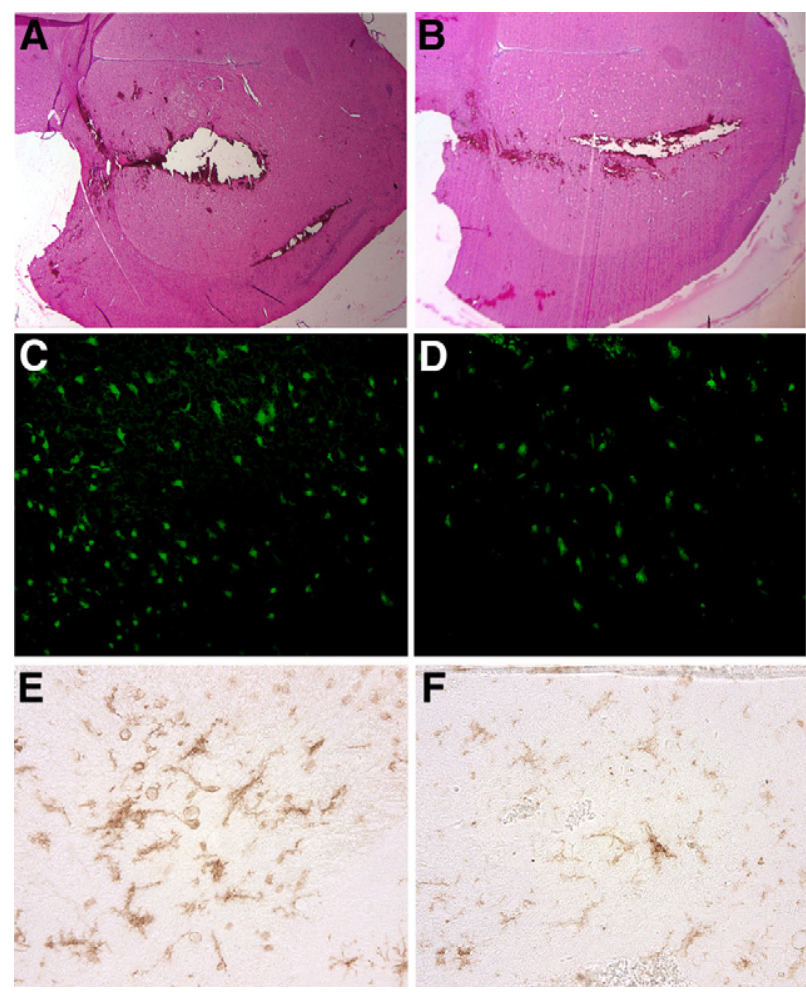

Figure 2. Histological consequences of ICH and the effect of minocycline applied in the blood that was used to create injury. Photomicrographs $\mathbf{A}$ to $\mathbf{F}$ show the histopathology of brain injury 24 hours after ICH. The area of brain damage (A and $\mathbf{B}$; H\&E stain), FJ-B positive dying neurons ( $\mathbf{C}$ and $\mathbf{D}$ ), and activity of microglia/macrophages (E and $\mathbf{F}$ ) are reduced by $10 \mu \mathrm{g} / \mathrm{ml}$ of minocycline $(\mathbf{B}, \mathbf{D}$, and $\mathbf{F}$ ) mixed within the blood that was used to create ICH compared with $\mathrm{PBS}$ vehicle $(\mathbf{A}, \mathbf{C}$, and $\mathbf{E})$. Original magnification: $\times 400$ $(\mathbf{C}-\mathbf{F}) ; \times 25$ (A and $\mathbf{B})$.

day IP for another 2 days. Control mice were given PBS through identical routes at these time points. All animals were sacrificed at day 21 after $\mathrm{ICH}$. All minocycline and vehicle solutions were matched for $\mathrm{pH}$.

\section{In Situ Zymography of Sections of Mouse Brain}

In situ zymography was used to detect the enzymatic activity of the gelatinases, MMP-2 and MMP-9, as previously described. ${ }^{30}$ The substrate for proteolytic degradation was gelatin. In brief, unfixed cryostat sections of 14- $\mu \mathrm{m}$ thickness were cut serially through the damaged brain. A reaction buffer containing $100 \mu \mathrm{g} / \mathrm{ml}$ of fluorescein isothiocyanate-labeled DQ-gelatin (EnzChek, Molecular Probes, Eugene, OR) was applied to these sections for 3 hours at $37^{\circ} \mathrm{C}$. Slides were washed, mounted, and photographed adjacent to the hematoma by a Spot digital camera using a $40 \times$ objective. Where gelatinolytic activity was present in brain tissue, the in situ degradation of fluorescein isothiocyanate-labeled DQ-gelatin resulted in emission of fluorescence at that location. Positive cells of gelatinolytic activity were counted in three photographic areas taken by the $40 \times$ objective, and the sum of the three fields per mouse was documented.

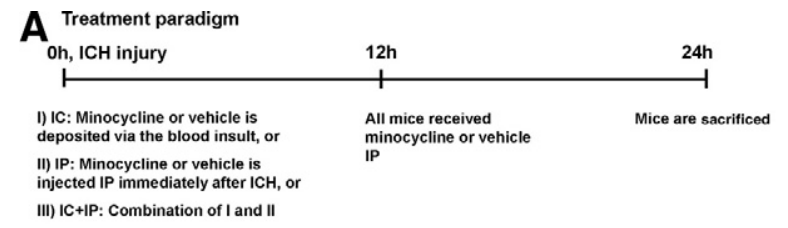

B Areas of brain damage
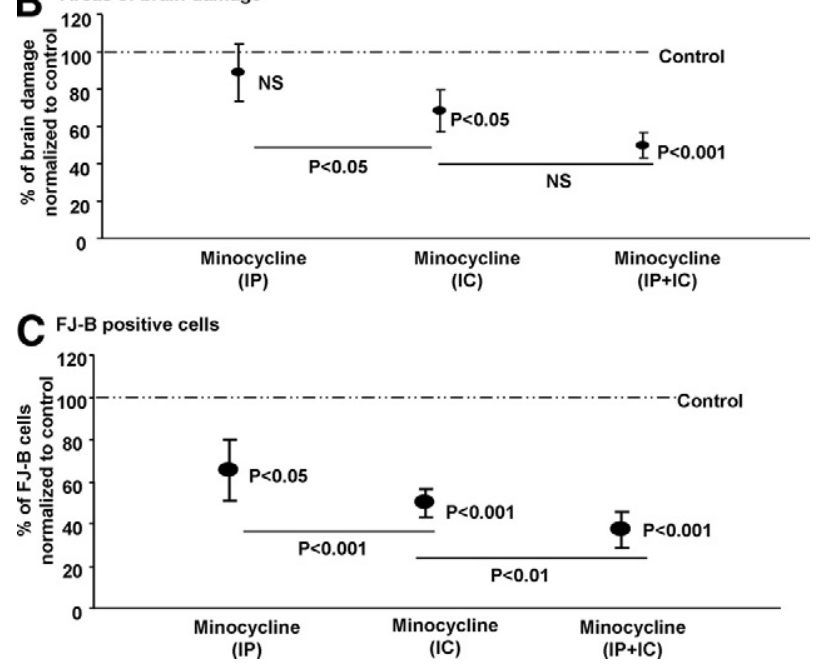

Figure 3. Brain damage and neuronal death after ICH are reduced by minocycline applied at time of injury. A: Descriptions of the treatments that were applied to mice are shown. Quantification of the area of brain damage (B) or number of dying neurons (C) at 24 hours after ICH was performed, and the data of minocycline-treated mice $(10 \mu \mathrm{g} / \mathrm{ml}$ mixed within the blood used to create injury) were expressed as the percent of that found in vehicletreated mice administered via the same route (IC). IC + IP minocycline resulted in very significant alleviation of injury, followed by IC administration. IP $(50 \mathrm{mg} / \mathrm{kg})$ minocycline reduced the number of FJ-B positive cells but did not lower the area of brain damage. The $P$ value of the minocycline group compared with their respective control group is indicated in the figure. There are six mice in each group. Analysis of variance followed by Bonferroni was used to analyze the results.

\section{Histopathological Evaluation}

Mice were sacrificed by an overdose of ketamine/xylazine and were cardiac perfused with ice cold $10 \%$ buffered formalin. The brains were removed, stored in the same fixative for 1 to 5 days, and then trimmed for coronal blocks approximately 2 to $3 \mathrm{~mm}$ on either side of the lesion epicenter. Blocks were dehydrated and embedded in paraffin. Coronal sections $(6 \mu \mathrm{m})$ were cut from the rostral to the caudal end of block; sections from three levels of brain were collected and analyzed following previously published protocols. ${ }^{30}$ These three sections per mouse per type of analysis included one from the lesion center and one each on either side spaced $120 \mu \mathrm{m}$ from the center section (Supplemental Figure 1, see http://ajp.amjpathol.org).

$H \& E$ staining was used to evaluate areas of brain damage, which were defined by the presence of blood, tissue rarefaction, or necrosis. ${ }^{30}$ Pictures of H\&E-stained sections were taken with a digital camera installed on the microscope by using a $2.5 \times$ objective, and ImagePro software (Media Cybernetics, Bethesda, MD) was used to trace and tabulate the area of damaged brain $\left(\mathrm{mm}^{2}\right)$ on each section (Supplemental Figure 1, see http://ajp. amjpathol.org). The sum from the three sections per 
mouse represents the area of brain damage per mouse. Analyses were conducted in a blinded manner.

Fluoro-Jade B (FJ-B) staining was used to assess dying neurons ${ }^{35}$ by incubating sections in potassium permanganate and Fluoro-Jade B (Histo-Chem Inc., Jefferson, AR) working solution. Ledar (Naphtyl AS-D Chloroacetate esterase, Sigma) staining was used to show granulocyte (neutrophil) infiltration. ${ }^{30}$ At high magnification (objective magnification $\times 40$ ) and aided by using an ocular reticule, the number of FJ-B positive neurons and neutrophils were counted in four fields immediately adjacent to hematoma as previously described ${ }^{30}$ (Supplemental Figure 1, see http:// ajp.amjpathol.org). The sum of four fields from three sections was used to depict the number of FJ-B positive cells per mouse. Analyses were evaluated blind.

We used anti-lba1 (ionized calcium-binding adapter molecule-1) antibody to address the status of activation of microglia/macrophages in $\mathrm{ICH}$ as previously described. ${ }^{30,36}$ In brief, stained sections were scored blindly for the morphology and density of activated microglia/macrophages by using a scale of 1 to 4 in which score 1 was of the least reactivity and score 4 was with the most reactivity. Considerations were made for the size, shape, and relative density of Iba1-labeled cells. In this regard, normal-resting microglia have many ramified processes projecting from the cell body. When activated, these processes begin to retract and thicken, and the microglia take on a more ameboid, macrophage-like appearance. In central nervous system (CNS) injuries, ameboid macrophages infiltrate the CNS parenchyma, and it becomes hard to differentiate the activated microglia from macrophages; thus, we refer to them collectively as microglia/macrophages.

\section{Behavioral Assessments}

Beginning 5 days before $\mathrm{ICH}$, mice were acclimated in an open field arena for behavioral testing. Mice were exposed to the open field every day for 5 days. Sessions were 5 minutes in duration. This procedure was important for minimizing fear and stress within the animals that could negatively influence behaviors during the test sessions. Three days after $\mathrm{ICH}$, mice were again placed in the open field environment where different functions were assessed by using different tests, specifically open field and grid walking tests. For open field locomotion (Autotrack system, Columbus Instruments, Columbus, $\mathrm{OH}$ ), the distance traveled $(\mathrm{cm})$, resting time (seconds), time spent in ambulatory activity (seconds), and number of vertical movements were recorded. Test sessions were 4 minutes in duration. Grid walking was used to evaluate motor coordination and balance by testing the ability of animals to traverse a reverted grid. Animals were videotaped and the number of drops made during a 3-minute interval was recorded. Analyses of mice were performed at 3,7 , and 14 days postinjury.

\section{Statistical Analyses}

All data are expressed as mean \pm SD. Intergroup comparisons were made by analysis of variance followed by Bonferroni. The differences were considered significant when $P<0.05$. We used GraphPad InStat software (LaJolla, CA) for statistical analyses.

\section{Results}

\section{Blood Is Toxic to Neurons in Culture and Death Is Attenuated by Minocycline in a Concentration-Dependent Manner}

We applied fresh human blood to neurons bathed with $100 \mu \mathrm{l}$ of culture medium. While $1 \mu \mathrm{l}$ of blood did not result in noticeable loss of neurons, 2.5 and $5 \mu$ resulted in the loss of $40 \%$ and $60 \%$ of neurons at 48 hours, respectively (Figure $1 \mathrm{~A}$ ).

Using $2.5 \mu \mathrm{l}$ of blood to induce death, we next tested the capacity of minocycline to protect neurons. Cells were pretreated with minocycline at 10,20 , or $40 \mu \mathrm{g} / \mathrm{ml}$ of minocycline for 10 minutes, and $2.5 \mu \mathrm{l}$ of blood was then added to the $100-\mu$ l culture medium. Figure 1B shows that the loss of microtubule-associated protein-2 stained neurons at 48 hours was attenuated in a concentrationdependent manner by minocycline. Figure 1, C-E, depicts images of neurons that demonstrate the protective effect of minocycline.

\section{Minocycline Reduces ICH Injury in Mice When Given at Time of Injury: Intracerebral Versus Systemic Administration}

At 24 hours after an injection of autologous blood into the brain, massive destruction of the striatum occurred, as depicted by loss of tissue, edema, and blood debris (Figure 2A). In contrast, ICH-afflicted mice treated with minocycline mixed into the blood that was used to create injury had reduced loss of tissue (Figure 2B). At the cellular level, compared with vehicle-treated $\mathrm{ICH}$ mice (Figure $2 \mathrm{C}$ ), minocycline-treated mice had less neuronal death as examined by FJ-B stain (Figure 2D). Similarly, microglia activation after $\mathrm{ICH}$ (Figure 2E) was reduced by minocycline (Figure 2F).

We quantified the histological outcomes at 24 hours after $\mathrm{ICH}$ in mice with intracerebral and/or i.p. routes of administration of minocycline (six mice per group). Because the volume of minocycline was different among the two routes $(2 \mu l$ intracerebral versus $100 \mu l$ i.p.), results were normalized to their respective vehicle controls administered in identical volume through the same route. Figure $3, \mathrm{~A}-\mathrm{C}$, shows that minocycline administered IP immediately after $\mathrm{ICH}$ did not reduce the area of brain damage, but the number of dying neurons detected by FJ-B was reduced. Minocycline administered within the blood (IC) that was used to create $\mathrm{ICH}$ resulted in a greater degree of protection from brain damage or dying neurons, while the best protection was afforded by minocycline given through the combined IC and IP routes.

Evaluation of neutrophil infiltration and microglia/macrophage activity (six mice per group) shows that these indices were not reduced by IP treatment of minocycline compared with vehicle (Supplemental Figure 2, see 


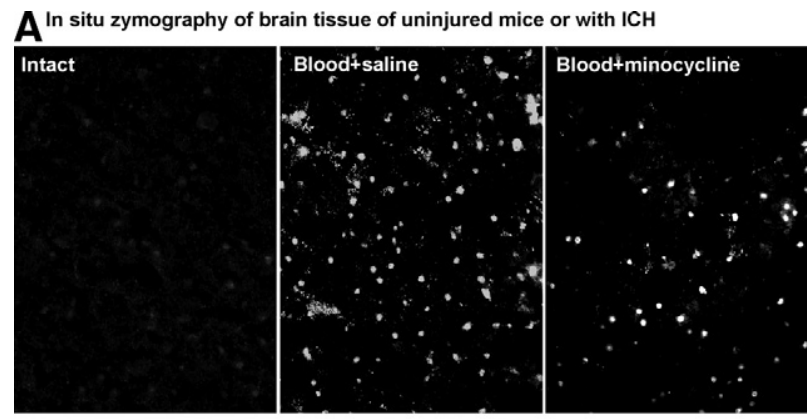

B Quantitation of In situ zymography

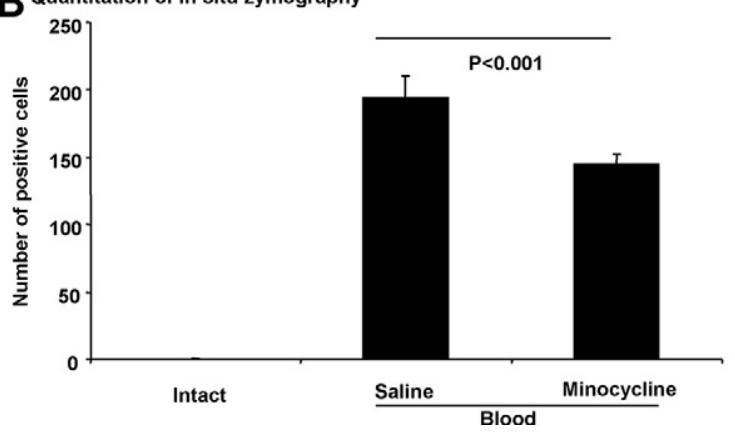

Figure 4. The increased gelatinolytic activity in ICH is reduced by minocycline. In situ zymography (A) shows negligible gelatinase activity in the uninjured intact brain (left); the increased gelatinolytic activity at 24 hours of $\mathrm{ICH}$ (middle) is reduced in treatment with minocycline (right). There are three mice per group. This figure shows brain areas adjacent to the hematoma. Original magnification, $\times 400$. B: The number of positive cells for in situ zymography at 24 hours of ICH is displayed.

http://ajp.amjpathol.org). However, minocycline mixed into the blood that was used to create $\mathrm{ICH}$ reduced neutrophil counts and activity of microglia/macrophages, and the best effect was achieved by the combination of IC and IP minocycline (Supplemental Figure 2, see http://ajp.amjpathol.org).

We have shown that in situ gelatinolytic activity (MMP-2 and MMP-9) is increased in this model of $\mathrm{ICH}^{32}$ To address whether minocycline suppress the gelatinolytic activity in $\mathrm{ICH}$, brain tissue around the hematoma was analyzed by using in situ zymography. Figure 4, A and B (three mice per group), shows that blood increases the number of positive cellular profiles, and the gelatinolytic activity is significantly reduced by minocycline treatment.

Overall, these results show that minocycline applied locally and immediately after injury alleviated histological evidence of brain damage at 24 hours, and this effect was enhanced when an IP injection was also applied at the time of the insult. The activity of MMP-2 and MMP-9 was also decreased significantly with minocycline.

\section{Delayed Intracerebral Treatment of Minocycline} Reduced ICH Injury in a Concentration-Dependent Manner

We next treated mice with $\mathrm{ICH}$ injury from 1 hour after the insult (Figure 5A). In the group treated locally with minocycline, the drug was injected as a $2-\mu$ l solution into the hematoma based on a hematoma volume of $10 \mu \mathrm{l}$. The final concentration of minocycline was thus calculated to
A Treatment paradigm

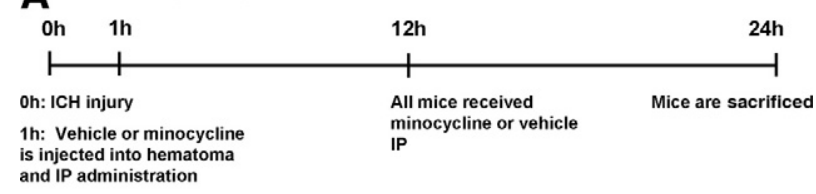
and IP administration

B Scattergram of area of brain damage

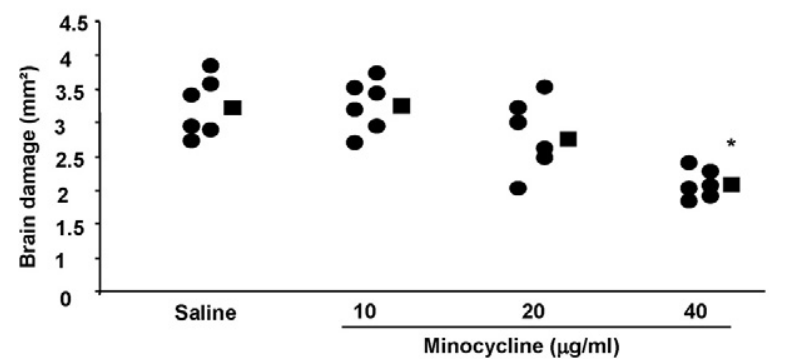

C Scattergram of FJ-B positive cells

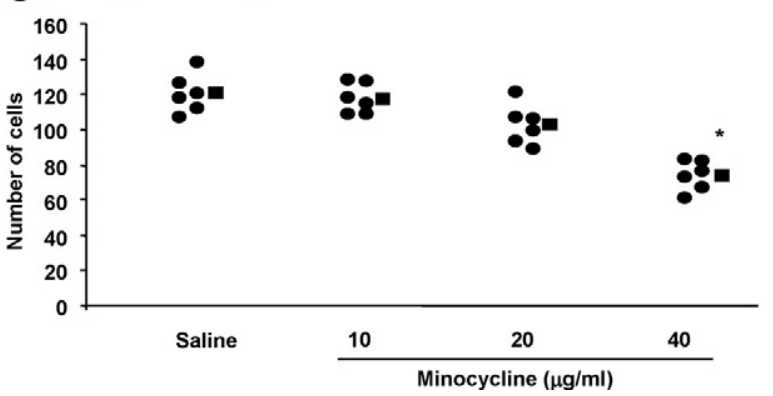

Figure 5. Brain damage and neuronal death after ICH are reduced by minocycline administered locally from 1 hour after injury (A). In $\mathbf{B}$ and $\mathbf{C}$, each circle represents individual mice while the square depicts the average of the group (six mice per group). The quantitative data show that brain damage areas $(\mathbf{B})$ and neuronal death $(\mathbf{C})$ are reduced by minocycline at 40 $\mu \mathrm{g} / \mathrm{ml}$ compared with intracerebral administration of PBS $\left({ }^{*} P<0.05\right)$, but lower concentrations of minocycline (10 and $20 \mu \mathrm{g} / \mathrm{ml}$ ) did not reach statistical significance $(P>0.05)$

be 10,20 , or $40 \mu \mathrm{g} / \mathrm{ml}$, but since the hematoma and brain injury volumes are likely to be larger than $10 \mu$, the concentrations of minocycline in the local brain environment are likely to be lower than these calculated values. After an additional dose of $50 \mathrm{mg} / \mathrm{kg}$ minocycline or vehicle was administered IP at 12 hours, all mice were sacrificed at 24 hours after $\mathrm{ICH}$ (six mice per group). We determined that the area of brain damage and the number of FJ-B positive dying neurons were reduced in a concentration-dependent manner, with a statistically significant difference attained by $40 \mu \mathrm{g} / \mathrm{ml}$ minocycline (Figure 5, B and $\mathrm{C}$ ). These results highlight that the higher the concentration of minocycline that is attained in the local environment around a lesion, the better the prospect of alleviating tissue injury.

\section{Minocycline's Long-term Outcomes after ICH When Administered through Intracerebral Plus Systemic Routes}

Since the results indicate that minocycline injected into the hematoma (IC) from 1 hour after injury reduced histopathology of $\mathrm{ICH}$ at 24 hours (Figure 5), we investigated whether there were longer term consequences to this 
A Grid walking test

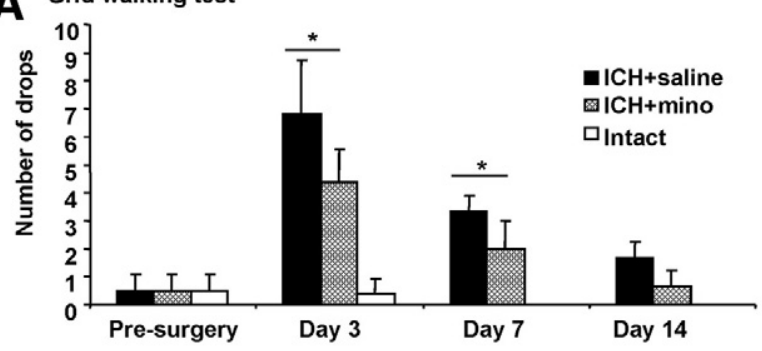

B Open field test

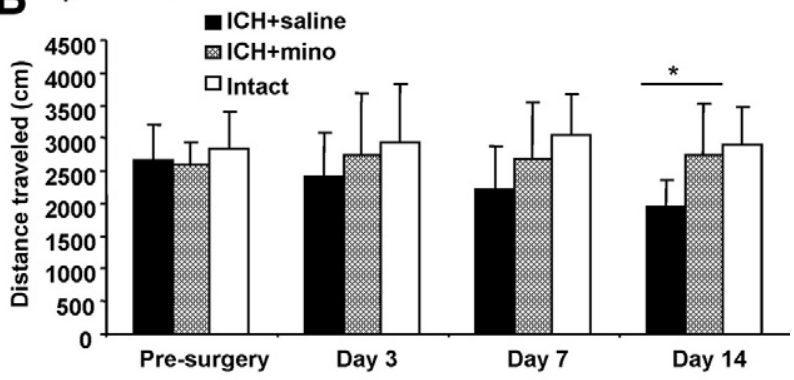

C Extent of brain damage

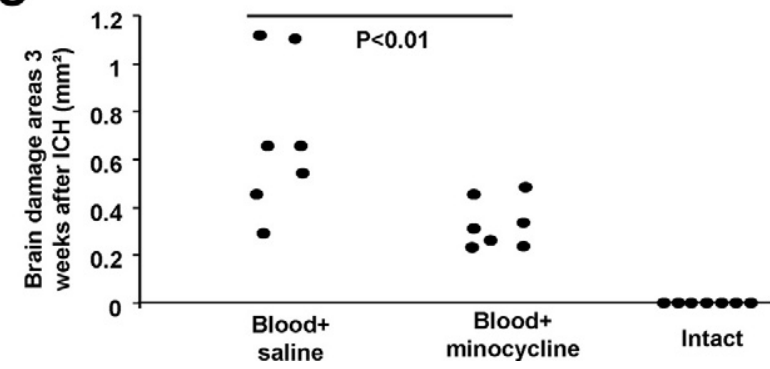

Figure 6. Evaluation of long-term behavioral recovery and brain tissue loss. Mice received intracerebral injections of blood and were treated by minocycline at 1 hour in both IC at $40 \mu \mathrm{g} / \mathrm{ml}$ based on a hematoma volume of $10 \mu \mathrm{l}$ and IP at $50 \mathrm{mg} / \mathrm{kg}$ followed by an additional $50 \mathrm{mg} / \mathrm{kg}$ of minocycline or PBS IP at 12 hours, then $50 \mathrm{mg} / \mathrm{kg}$ IP twice a day for the next 3 days, which was then tapered to $50 \mathrm{mg} / \mathrm{kg}$ per day for another 2 days. Bar graphs (mean \pm SD) show that the number of drops in the grid walking test $(\mathbf{A})$ is significantly reduced at day 3 and day 7 compared with PBS treatment, but this was not maintained at day 14 (seven mice per group in $\mathbf{A}$ and $\mathbf{B}$ ). The distance traveled in the open field test is significantly improved at day 14 compared with PBS treatment $(\mathbf{B})$; however, these open field results have to be treated cautiously since presurgery and postsurgery values were not different in all groups, calling into question the reliability of open field scores in this model of ICH. In $\mathbf{C}$, long-term brain damage areas are significantly reduced by delayed minocycline treatment after $\mathrm{ICH}$. Each dot in $\mathbf{C}$ shows an individual mouse, and there were seven mice per group. ${ }^{*} P<0.05$ compared with vehicle control.

outcome. Thus, mice after ICH were initiated minocycline (40 $\mu \mathrm{g} / \mathrm{ml}$ based on a hematoma volume of $10 \mu \mathrm{l}$ ) or vehicle injected into the hematoma at 1 hour after injury, and IP injections of minocycline $(50 \mathrm{mg} / \mathrm{kg})$ or PBS, respectively, at 1,12 , and 24 hours, then twice a day from days 2 to 4 , and once a day at days 5 and 6 . Treatment was then terminated. Mice were subjected to behavioral analyses at days 3,7 , and 14 . The results (seven mice per group) show that grid walking in the early period (3 and 7 days) after $\mathrm{ICH}$ was significantly improved by minocycline compared with vehicle treatment (Figure 6, A-C). However, this difference was not maintained at day 14 , likely attributed in part to improvement in grid walking in $\mathrm{ICH}$ mice administered vehicle when compared with the immediate post-ICH level.
With regards to open field (distance traveled) performance, while a statistical difference was found between the minocycline and vehicle treatment $\mathrm{ICH}$ groups at day 14, we did not detect differences at earlier time points of analyses. Indeed, the three test groups (intact, $\mathrm{ICH}+$ vehicle, $\mathrm{ICH}+$ minocycline) did not differ in distance traveled between presurgery and postsurgery, calling into question whether the open field could address functional deficits after $\mathrm{ICH}$ in the striatum.

On sacrifice 21 days after $\mathrm{ICH}$, we observed that the brain of mice had healed substantially from the outcome noted at 24 hours; hematoma was no longer visible, and the edema and necrotic core evident at 24 hours was not readily apparent. The work of other authors ${ }^{37}$ has indicated that rodent brains heal progressively after $\mathrm{ICH}$ injury, and this is reflected in our finding of a smaller brain damage area at day 21 relative to 24 hours (compare Figure $6 \mathrm{C}$ to Figure 5B, respectively, of values from the vehicle treatment groups). Significantly, the remaining area of brain damage at day 21 was smaller in the mice given minocycline after $\mathrm{ICH}$ compared with PBS treatment (Figure 6C).

\section{Discussion}

A large body of literature emphasizes the remarkable capacity of minocycline to provide for beneficial outcomes such as neuroprotection after insults to the CNS. ${ }^{1-9}$ These insults include acute injuries with rapid onset of neuropathology, such as stroke, head trauma, and spinal cord injury, as well as chronic conditions such as Parkinson's disease, ALS, and multiple sclerosis. The mechanisms underlying the usefulness of minocycline across a diverse number of neurological conditions are still unresolved but main attributes include its anti-inflammatory, antiapoptotic, and other activities such as inhibition of MMPs. ${ }^{9-12}$ These effects can be achieved in the periphery as well as within the CNS because minocycline is lipophilic and has access into the CNS parenchyma. Despite the large body of literature emphasizing the utility of minocycline, there are many authors who refute these claims in all of the conditions listed above. For example, in spinal cord injury in rodents, the administration of minocycline post-trauma has been reported by several groups to produce limited ${ }^{38}$ or remarkable desirable outcomes such as the reduction of apoptosis of neurons, the relative preservation of axonal tracts that traverse the area of impact, and improved functional recovery; ${ }^{4,5,39-42}$ in contrast, other authors ${ }^{43,44}$ could not find favorable outcomes for minocycline after spinal cord injury in rats. In the chronic condition of multiple sclerosis, studies in experimental models revealed minocycline to attenuate clinical signs and the extent of neuropathology in the spinal cord or optic nerve, ${ }^{5,6,31,45}$ but Nessler et al ${ }^{46}$ did not observe any benefit. The latter, however, used orally administered minocycline in contrast to parenteral minocycline described for the other studies.

Overall, for the experimental conditions studied, it is estimated that about 10 to $20 \%$ of the literature could not produce the favorable results of the majority. The reason 
for this discrepancy is important to resolve given that minocycline has progressed to clinical trials in neurological disorders where promising results have been found in stroke ${ }^{17}$ and multiple sclerosis, ${ }^{13-15}$ but where highdose (400 mg/d oral) minocycline given over 9 months worsened or did not benefit ALS. ${ }^{16}$ On the basis of favorable preclinical ${ }^{3,5}$ and pilot clinical results from our group, ${ }^{13-15}$ our center is leading an ongoing Phase III trial of minocycline in first-episode multiple sclerosis (200 $\mathrm{mg} / \mathrm{d}$ oral; clinicaltrials.gov, identifier NCT00666887) and concluding a pilot clinical trial of intravenous minocycline (800 mg/d, for 7 days) in acute spinal cord injury (clinicaltrials.gov, identifier NCT00559494).

Because of the promise of minocycline in neurological sciences, but because of the discrepancy, it is important to address factors that may influence the discrepant results described earlier. Several factors are likely contributory, including the physical chemistry of minocycline, its pharmacokinetics in human and experimental models, the consideration of treatment in acute versus chronic neurological conditions, the dose and the route of administration, and considerations of peripheral or central targets of the medication in the respective conditions. With regards to the physical chemistry of minocycline, this is a very unstable compound and constitution in solution rapidly leads to its autooxidation, which is evident in the change of coloration of the solution over time. Thus, the use of fresh solutions is critical to increase the odds of achieving neuroprotection. Minocycline also has solubility problems, and the higher concentration of solution required for the same dose in rats versus mice necessitates ensuring that minocycline is dissolved well when used in the larger rodent species. With regards to pharmacokinetics, it is important to note that while minocycline has a half life of about 15 hours in humans, ${ }^{47,48}$ its half life in mice is about 2 hours. ${ }^{33,34}$ Thus, more frequent administration of minocycline and using larger doses per kilogram of body weight is necessary in rodents (Supplemental Table 1, see http://ajp.amjpathol.org) ${ }^{2,10,18-26}$ to achieve steady state concentrations in serum comparable with those in humans.

The current study was conducted with the goal of further defining some of the variables that might contribute to the improved effectiveness of minocycline. We chose a model of ICH given that significant neuropathology could be observed within 24 hours and given that there are controversies with regards to the outcomes of minocycline in this condition in rodents. On the basis of tissue culture results that indicate the importance of achieving a high concentration of minocycline to observe neuroprotection, we sought first to provide local high concentrations of minocycline around the hematoma by applying minocycline directly with the blood that was used to inflict damage, or by injecting minocycline into the area of the hematoma 1 hour after the insult. Our results indicate that local administrations, particularly when applied at higher concentrations, reduced the number of dying neurons and the extent of brain damage, and promoted limited functional recovery compared with only i.p. administration of the medication. The latter could supplement the usefulness of the centrally administered minocycline, likely since the systemic injections provide a peripheral pool of minocycline to access the CNS parenchyma over time.

In considering a condition such as $\mathrm{ICH}$, in which neural elements are undergoing degeneration promoted by injury inflicted within the CNS as well as by the infiltration of inflammatory cells from the periphery, it appears pertinent that a local and high concentration of minocycline is achieved within the CNS milieu to reduce neural damage. Moreover, the systemic effects of minocycline, manifested by reduction of neutrophil influx into the CNS, likely help account for the protective responses observed with minocycline in this study. In contrast, where infiltration of leukocytes into the CNS parenchyma is a major cause of neuropathology, such as in multiple sclerosis, the local concentration of minocycline in the CNS parenchyma may be less vital compared with the concentration available in the systemic circulation.

We are cognizant that factors other than pharmacokinetics and local cerebral concentrations may contrast the negative results of minocycline in the ALS trial ${ }^{16}$ and its promising impact in multiple sclerosis ${ }^{13-15}$ and stroke. ${ }^{17}$ The capacity of minocycline to reduce the robust inflammatory response directed to the CNS from the periphery in multiple sclerosis and stroke may be more easily achieved than the presumed centrally-mediated neuronal death occurring in ALS. Moreover, microglia activation in ALS may have beneficial roles such as protecting neurons from the underlying causes of neuropathology ${ }^{49}$ so the long-term use of minocycline in the ALS trial may have hindered chronically a protective response. Clearly, these are additional considerations in planning for future trials in neurological diseases.

In summary, the data in this article support the capacity of minocycline to confer neuroprotection after an acute injury to neurons. We provide results that suggest that by using high concentrations of minocycline, the outcomes of acute neurological insults are improved. We provide methods that show how to deliver minocycline locally within the CNS parenchyma and with supplementation by systemic administration. Our findings have relevance to the increasing appreciation that minocycline is not only neuroprotective if used adequately, but that it can increase the effectiveness and time window for tissue plasminogen activator treatment in ischemic strokes. ${ }^{50,51}$

\section{Acknowledgments}

We thank Shuhong Liu, Yan Fan, and Brooke Verhaeghe for skilled technical assistance.

\section{References}

1. Yrjanheikki J, Keinanen R, Pellikka M, Hokfelt T, Koistinaho J: Tetracyclines inhibit microglial activation and are neuroprotective in global brain ischemia. Proc Natl Acad Sci USA 1998, 95:15769-15774

2. Arvin KL, Han BH, Du Y, Lin SZ, Paul SM, Holtzman DM: Minocycline markedly protects the neonatal brain against hypoxic-ischemic injury. Ann Neurol 2002, 52:54-61

3. Wells JE, Hurlbert RJ, Fehlings MG, Yong VW: Neuroprotection by 
minocycline facilitates significant recovery from spinal cord injury in mice. Brain 2003, 126:1628-1637

4. Lee SM, Yune TY, Kim SJ, Park DW, Lee YK, Kim YC, Oh YJ, Markelonis GJ, Oh TH: Minocycline reduces cell death and improves functional recovery after traumatic spinal cord injury in the rat. $J$ Neurotrauma 2003, 20:1017-1027

5. Brundula V, Rewcastle NB, Metz LM, Bernard CC, Yong VW: Targeting leukocyte MMPs and transmigration: minocycline as a potential therapy for multiple sclerosis. Brain 2002, 125:1297-1308

6. Popovic N, Schubart A, Goetz BD, Zhang SC, Linington C, Duncan ID: Inhibition of autoimmune encephalomyelitis by a tetracycline. Ann Neurol 2002, 51:215-223

7. Du Y, Ma Z, Lin S, Dodel RC, Gao F, Bales KR, Triarhou LC, Chernet E, Perry KW, Nelson DL, Luecke S, Phebus LA, Bymaster FP, Paul SM: Minocycline prevents nigrostriatal dopaminergic neurodegeneration in the MPTP model of Parkinson's disease. Proc Natl Acad Sci USA 2001, 98:14669-14674

8. Wu DC, Jackson-Lewis V, Vila M, Tieu K, Teismann P, Vadseth C, Choi DK, Ischiropoulos H, Przedborski S: Blockade of microglial activation is neuroprotective in the 1-methyl-4-phenyl-1,2,3,6-tetrahydropyridine mouse model of Parkinson disease. J Neurosci 2002, 22:1763-1771

9. Stirling DP, Koochesfahani KM, Steeves JD, Tetzlaff W: Minocycline as a neuroprotective agent. Neuroscientist 2005, 11:308-322

10. Yong VW, Wells J, Giuliani F, Casha S, Power C, Metz LM: The promise of minocycline in neurology. Lancet Neurol 2004, 3:744-751

11. Zemke D, Majid A: The potential of minocycline for neuroprotection in human neurologic disease. Clin Neuropharmacol 2004, 27:293-298

12. Elewa HF, Hilali H, Hess DC, Machado LS, Fagan SC: Minocycline for short-term neuroprotection. Pharmacotherapy 2006, 26:515-521

13. Metz LM, Zhang Y, Yeung M, Patry DG, Bell RB, Stoian CA, Yong VW, Patten SB, Duquette P, Antel JP, Mitchell JR: Minocycline reduces gadolinium-enhancing magnetic resonance imaging lesions in multiple sclerosis. Ann Neurol 2004, 55:756

14. Zabad RK, Metz LM, Todoruk TR, Zhang Y, Mitchell JR, Yeung M, Patry DG, Bell RB, Yong VW: The clinical response to minocycline in multiple sclerosis is accompanied by beneficial immune changes: a pilot study. Mult Scler 2007, 13:517-526

15. Zhang Y, Metz LM, Yong VW, Bell RB, Yeung M, Patry DG, Mitchell JR: Pilot study of minocycline in relapsing-remitting multiple sclerosis. Can J Neurol Sci 2008, 35:185-191

16. Gordon PH, Moore DH, Miller RG, Florence JM, Verheijde JL, Doorish C, Hilton JF, Spitalny GM, MacArthur RB, Mitsumoto H, Neville HE, Boylan K, Mozaffar T, Belsh JM, Ravits J, Bedlack RS, Graves MC, McCluskey LF, Barohn RJ, Tandan R: Efficacy of minocycline in patients with amyotrophic lateral sclerosis: a phase III randomised trial. Lancet Neurol 2007, 6:1045-1053

17. Lampl Y, Boaz M, Gilad R, Lorberboym M, Dabby R, Rapoport A, Anca-Hershkowitz M, Sadeh M: Minocycline treatment in acute stroke: an open-label, evaluator-blinded study. Neurology 2007, 69:1404-1410

18. Szymanska A, Biernaskie J, Laidley D, Granter-Button S, Corbett D: Minocycline and intracerebral hemorrhage: influence of injury severity and delay to treatment. Exp Neurol 2006, 197:189-196

19. Wasserman JK, Schlichter LC: Neuron death and inflammation in a rat model of intracerebral hemorrhage: effects of delayed minocycline treatment. Brain Res 2007, 1136:208-218

20. Wu J, Yang S, Xi G, Fu G, Keep RF, Hua Y: Minocycline reduces intracerebral hemorrhage-induced brain injury. Neurol Res 2009, 31:183-188

21. Fox C, Dingman A, Derugin N, Wendland MF, Manabat C, Ji S, Ferriero DM, Vexler ZS: Minocycline confers early but transient protection in the immature brain following focal cerebral ischemia-reperfusion. J Cereb Blood Flow Metab 2005, 25:1138-1149

22. Tsuji M, Wilson MA, Lange MS, Johnston MV: Minocycline worsens hypoxic-ischemic brain injury in a neonatal mouse model. Exp Neurol 2004, 189:58-65

23. Yrjanheikki J, Tikka T, Keinanen R, Goldsteins G, Chan PH, Koistinaho $\mathrm{J}$ : A tetracycline derivative, minocycline, reduces inflammation and protects against focal cerebral ischemia with a wide therapeutic window. Proc Natl Acad Sci USA 1999, 96:13496-13500

24. Wang CX, Yang T, Noor R, Shuaib A: Delayed minocycline but not delayed mild hypothermia protects against embolic stroke. BMC Neurol 2002, 2:2
25. Xu L, Fagan SC, Waller JL, Edwards D, Borlongan CV, Zheng J, Hill WD, Feuerstein G, Hess DC: Low dose intravenous minocycline is neuroprotective after middle cerebral artery occlusion-reperfusion in rats. BMC Neurol 2004, 4:7

26. Hayakawa K, Mishima K, Nozako M, Hazekawa M, Mishima S, Fujioka M, Orito K, Egashira N, Iwasaki K, Fujiwara M: Delayed treatment with minocycline ameliorates neurologic impairment through activated microglia expressing a high-mobility group box1-inhibiting mechanism. Stroke 2008, 39:951-958

27. Li J, McCullough LD: Sex differences in minocycline-induced neuroprotection after experimental stroke. J Cereb Blood Flow Metab 2009, 29:670-674

28. Power C, Henry S, Del Bigio MR, Larsen PH, Corbett D, Imai Y, Yong VW, Peeling J: Intracerebral hemorrhage induces macrophage activation and matrix metalloproteinases. Ann Neurol 2003, 53:731-742

29. Vecil GG, Larsen PH, Corley SM, Herx LM, Besson A, Goodyer CG, Yong VW: Interleukin-1 is a key regulator of matrix metalloproteinase-9 expression in human neurons in culture and following mouse brain trauma in vivo. J Neurosci Res 2000, 61:212-224

30. Xue M, Hollenberg MD, Yong VW: Combination of thrombin and MMP-9 exacerbates neurotoxicity in cell culture and intracerebral hemorrhage in mice. J Neurosci 2006, 26:10281-10291

31. Maier K, Merkler D, Gerber J, Taheri N, Kuhnert AV, Williams SK, Neusch C, Bahr M, Diem R: Multiple neuroprotective mechanisms of minocycline in autoimmune CNS inflammation. Neurobiol Dis 2007, 25:514-525

32. Xue M, Fan Y, Liu S, Zygun DA, Demchuk A, Yong VW: Contributions of multiple proteases to neurotoxicity in a mouse model of intracerebral haemorrhage. Brain 2009, 132:26-36

33. Andes D, Craig WA: Animal model pharmacokinetics and pharmacodynamics: a critical review. Int J Antimicrob Agents 2002, 19:261-268

34. Fagan SC, Edwards DJ, Borlongan CV, Xu L, Arora A, Feuerstein G, Hess DC: Optimal delivery of minocycline to the brain: implication for human studies of acute neuroprotection. Exp Neurol 2004, 186:248-251

35. Schmued LC, Albertson C, Slikker W, Jr.: Fluoro-Jade: a novel fluorochrome for the sensitive and reliable histochemical localization of neuronal degeneration. Brain Res 1997, 751:37-46

36. Wells JE, Biernaskie J, Szymanska A, Larsen PH, Yong VW, Corbett D: Matrix metalloproteinase (MMP)-12 expression has a negative impact on sensorimotor function following intracerebral haemorrhage in mice. Eur J Neurosci 2005, 21:187-196

37. MacLellan CL, Silasi G, Poon CC, Edmundson CL, Buist R, Peeling J, Colbourne F: Intracerebral hemorrhage models in rat: comparing collagenase to blood infusion. J Cereb Blood Flow Metab 2008, 28:516-525

38. Saganova K, Orendacova J, Cizkova D, Vanicky I: Limited minocycline neuroprotection after balloon-compression spinal cord injury in the rat. Neurosci Lett 2008, 433:246-249

39. Stirling DP, Khodarahmi K, Liu J, McPhail LT, McBride CB, Steeves JD, Ramer MS, Tetzlaff W: Minocycline treatment reduces delayed oligodendrocyte death, attenuates axonal dieback, and improves functional outcome after spinal cord injury. J Neurosci 2004, 24: 2182-2190

40. Teng YD, Choi H, Onario RC, Zhu S, Desilets FC, Lan S, Woodard EJ, Snyder EY, Eichler ME, Friedlander RM: Minocycline inhibits contusion-triggered mitochondrial cytochrome $\mathrm{c}$ release and mitigates functional deficits after spinal cord injury. Proc Natl Acad Sci USA 2004, 101:3071-3076

41. Festoff BW, Ameenuddin S, Arnold PM, Wong A, Santacruz KS, Citron BA: Minocycline neuroprotects, reduces microgliosis, and inhibits caspase protease expression early after spinal cord injury. J Neurochem 2006, 97:1314-1326

42. Yune TY, Lee JY, Jung GY, Kim SJ, Jiang MH, Kim YC, Oh YJ, Markelonis GJ, Oh TH: Minocycline alleviates death of oligodendrocytes by inhibiting pro-nerve growth factor production in microglia after spinal cord injury. J Neurosci 2007, 27:7751-7761

43. Pinzon A, Marcillo A, Quintana A, Stamler S, Bunge MB, Bramlett HM, Dietrich WD: A re-assessment of minocycline as a neuroprotective agent in a rat spinal cord contusion model. Brain Res 2008, 1243:146-151 
44. Zang DW, Cheema SS: Leukemia inhibitory factor promotes recovery of locomotor function following spinal cord injury in the mouse. J Neurotrauma 2003, 20:1215-1222

45. Hu W, Metselaar J, Ben LH, Cravens PD, Singh MP, Frohman EM, Eagar TN, Racke MK, Kieseier BC, Stuve O: PEG minocycline-liposomes ameliorate CNS autoimmune disease. PLoS ONE 2009, 4:e4151

46. Nessler S, Dodel R, Bittner A, Reuss S, Du Y, Hemmer B, Sommer N: Effect of minocycline in experimental autoimmune encephalomyelitis. Ann Neurol 2002, 52:689-690; author reply 690

47. Cartwright AC, Hatfield HL, Yeadon A, London E: A comparison of the bioavailability of minocycline capsules and film-coated tablets. J Antimicrob Chemother 1975, 1:317-322

48. Agwuh KN, MacGowan A: Pharmacokinetics and pharmacodynam- ics of the tetracyclines including glycylcyclines. J Antimicrob Chemother 2006, 58:256-265

49. Beers DR, Henkel JS, Xiao Q, Zhao W, Wang J, Yen AA, Siklos L, McKercher SR, Appel SH: Wild-type microglia extend survival in PU. 1 knockout mice with familial amyotrophic lateral sclerosis. Proc Natl Acad Sci USA 2006, 103:16021-16026

50. Murata Y, Rosell A, Scannevin RH, Rhodes KJ, Wang X, Lo EH Extension of the thrombolytic time window with minocycline in experimental stroke. Stroke 2008, 39:3372-3377

51. Machado LS, Sazonova IY, Kozak A, Wiley DC, El-Remessy AB, Ergul A, Hess DC, Waller JL, Fagan SC: Minocycline and tissue-type plasminogen activator for stroke: assessment of interaction potential. Stroke 2009, 40:3028-3033 